\title{
Hypooxytocinaemia in obese Zucker rats relates to oxytocin degradation in liver and adipose tissue
}

\author{
Lucia Gajdosechova', Katarina Krskova', Ana Belen Segarra², Andrea Spolcova ${ }^{3}$, \\ Maciej Suski ${ }^{4}$, Rafal Olszanecki ${ }^{4}$ and Stefan Zorad ${ }^{1}$ \\ ${ }^{1}$ Institute of Experimental Endocrinology, Slovak Academy of Sciences, Vlarska 3, 83306 Bratislava, Slovakia \\ ${ }^{2}$ Unit of Physiology, Department of Health Sciences, University of Jaen, 23071 Jaen, Spain \\ ${ }^{3}$ Institute of Organic Chemistry and Biochemistry, Czech Academy of Sciences, 16610 Prague, Czech Republic \\ ${ }^{4}$ Chair of Pharmacology, Jagiellonian University Medical College, 31531 Krakow, Poland
}

\author{
Correspondence \\ should be addressed \\ to L Gajdosechova \\ Email \\ lucia.gajdosechova@savba.sk
}

\begin{abstract}
The metabolic action of oxytocin has recently been intensively studied to assess the ability of the peptide to regulate energy homeostasis. Despite the obvious weight-reducing effect of oxytocin observed in experimental studies, plasma oxytocin levels were found to be unchanged or even elevated in human obesity. The aim of our study was to evaluate the changes in the oxytocin system in Zucker rats, an animal model closely mirroring morbid obesity in humans. Plasma oxytocin levels were measured in obese Zucker rats and lean controls by enzyme immunoassay after plasma extraction. The expression of oxytocin and oxytocin receptor (OXTR) was assessed at the mRNA and protein levels by quantitative real-time PCR and immunoblotting respectively. Plasma and tissue activity of oxytocinase, the main enzyme involved in oxytocin degradation, were measured by fluorometric assay using an arylamide derivate as the substrate. Obese Zucker rats displayed a marked reduction in plasma oxytocin levels. Elevated liver and adipose tissue oxytocinase activity was noticed in obese Zucker rats. Hypothalamic oxytocin gene expression was not altered by the obese phenotype. OXTR mRNA and protein levels were upregulated in the adipose tissue of obese animals in contrast to the reduced OXTR protein levels in skeletal muscle. Our results show that obesity is associated with reduced plasma oxytocin due to increased peptide degradation by liver and adipose tissue rather than changes in hormone synthesis. This study highlights the importance of the oxytocin system in the pathogenesis of obesity and suggests oxytocinase inhibition as a candidate approach in the therapy of obesity.
\end{abstract}

\author{
Key Words \\ - oxytocin \\ - obesity \\ - insulin resistance \\ - oxytocinase \\ - oxytocin receptor
}

\section{Introduction}

The neuropeptide oxytocin is a hormone with a wide range of central and peripheral effects. Besides its well-known role in labour and lactation (Gimpl \& Fahrenholz 2001), oxytocin is released in response to various stress stimuli (Jezova et al. 1995) and is considered to be a cardiovascular hormone as well (Gutkowska et al. 2000, Ondrejcakova et al. 2009). Central oxytocin action includes behavioural effects and an effect on memory (Gimpl \& Fahrenholz 2001). Centrally released oxytocin also plays a role in the regulation of food intake, acting as an anorexigenic peptide through continuation of the melanocortin pathway. The ability of oxytocin to reduce food intake is linked to limitation of 
meal size and enhancement of the effectiveness of peripheral satiety signals (Leng et al. 2008). Recently, we have shown that peripherally administered oxytocin at a low dose is inefficient at inhibiting food intake and stimulates adipogenesis in vivo without affecting adipose tissue mass (Eckertova et al. 2011). Other studies have revealed the weight-reducing action of oxytocin treatment due to oxytocin-induced anorexia with a positive effect on glucose tolerance and insulin sensitivity (Deblon et al. 2011, Maejima et al. 2011, Morton et al. 2012, Zhang et al. 2013).

In vivo physiological levels of circulating oxytocin depend on its synthesis, receptor-mediated internalisation and degradation by oxytocinase. Oxytocinase (cystinyl aminopeptidase, EC 3.4.11.3) is an enzyme that inactivates oxytocin via hydrolysis of the peptide bonds between cysteine and tyrosine (Rogi et al. 1996, Keller 2003, Wallis et al. 2007). The liver and kidney have been shown to be responsible for the majority of oxytocin degradation (Sjoholm \& Ryden 1969, Fjellestad-Paulsen \& Lundin 1996). So far, to our knowledge, no data describing the comprehensive regulation of oxytocin levels in obesity, including peptide synthesis, internalisation and degradation, exist.

Nowadays, clarification the metabolic effects of oxytocin is based on genetic studies (Takayanagi et al. 2008, Camerino 2009) and pharmacological insights (Deblon et al. 2011, Eckertova et al. 2011, Maejima et al. 2011). As previous studies mapping the changes in plasma oxytocin levels in obesity have reported conflicting results (Stock et al. 1989, Schroeder et al. 2009, Morton et al. 2012), we aimed to determine whether obesity is associated with plasma oxytocin reduction and whether this change (if any) is a result of altered peptide production or degradation.

The Zucker fatty rat represents a well-established model of human obesity and insulin resistance. Obesity in this animal model is a consequence of spontaneous mutation $(\mathrm{fa})$ in the gene encoding the leptin receptor resulting in hyperphagia (Phillips et al. 1996). Thus, the obese Zucker rats are leptin resistant and related comorbidities associated with obesity also develop. We believe that the results obtained on oxytocin metabolism in Zucker rats provide an integrative insight into the regulation of the oxytocin system in obesity.

\section{Materials and methods}

\section{Animals}

Male Zucker fatty rats (fa/fa) and their lean controls (+/?) aged 9 weeks were purchased from Harlan (Udine, Italy).
Animals were maintained on $12 \mathrm{~h}$ light: $12 \mathrm{~h}$ darkness cycle and allowed ad libitum access to water and standard diet. Overnight-fasted rats were killed by decapitation at the age of 33 weeks. Experimental procedures and animal care were carried out according to the regulations of the Jagiellonian University Ethical Committee on Animal Experiments.

\section{Measurement of plasma oxytocin and selected metabolic parameters}

Plasma oxytocin levels were measured in duplicate by enzyme immunoassay (EIA) (Phoenix Pharmaceuticals, Burlingame, CA, USA) after plasma peptide extraction on C-18 SEP COLUMN, following the manufacturer's instruction. Precision of the assay declared by the manufacturer is as follows: intra-assay variation $<10 \%$; inter-assay variation $<15 \%$. Plasma leptin and insulin levels were evaluated by RIA kits (Millipore, Bedford, MA, USA). Lipid profile determination was performed in the Laboratory Diagnostics Unit of The University Hospital in Krakow using commercially available kits (Roche Molecular Diagnostics). In order to determine glucose tolerance, rats were subjected to intraperitoneal glucose tolerance test (IPGTT) after an overnight fast. The rats were administered an i.p. injection of 50\% dextrose (w/v) at a dose of $2 \mathrm{~g} / \mathrm{kg}$ body weight. The blood glucose was measured in the tail vein blood prior to and 30 , 60, 90 and $120 \mathrm{~min}$ after glucose administration using a glucometer (Accu-Check Active, Roche Diagnostics). Rats were allowed 2 days to recover from IPGTT prior to decapitation followed by plasma and tissue sample collection.

\section{RNA isolation and real-time PCR}

Total RNA was isolated from frozen tissues using an RNeasy Universal Plus Mini Kit (Qiagen) followed by RT using a Maxima First Strand cDNA Synthesis Kit (Thermo Fisher, Waltham, MA, USA). Real-time qPCR was performed on an ABI 7900HT thermal cycler (Applied Biosystems, Life Technologies) using Maxima Sybr Green qPCR Master Mix (Thermo Fisher). Primers used for qPCR are shown in Table 1. Because of the high homology of the oxytocin and vasopressin genes, we used the Oxytocin TaqMan Gene Expression Assay (Rn00564446_g1; Applied Biosystems, Life Technologies) to evaluate hypothalamic oxytocin mRNA expression. Gene expression of fat mass and obesity associated (Fto) was determined by TaqMan Gene Expression Assay (Rn01538187_m1; Applied Biosystems, Life Technologies). Obtained data were normalised to expression of the housekeeping gene ribosomal protein S29 (Rps29)

Published by Bioscientifica Ltd 
Table 1 Primer sequences used for qPCR

\begin{tabular}{l} 
Gene \\
\hline Rn18s \\
Cd68 \\
Glut1 \\
II10 \\
Oxytocinase \\
Oxtr \\
Rps29 \\
Syt4 \\
Tnfa
\end{tabular}

\begin{tabular}{l} 
Forward \\
\hline $5^{\prime}$-GGGAGGTAGTGACGAAAAATAACAAT-3' \\
5'-CCATCCCCACTTGGCTCTCT-3' \\
5'-TGTGCAGCAGCCTGTGTATG-3' \\
5'-CCCTGGGAGAGAAGCTGAAGA-3' \\
5'-GGCACATCAGTGGTTTGGTAATC-3' \\
5'-TTCTTCTGCTGCTCTGCTCGT-3' \\
5'-GCTGAACATGTGCCGACAGT-3' \\
5'-CGCGTGGAATTCGATGAAAT-3' \\
5'-CCACCACGCTCTTCTGTCTAC-3'
\end{tabular}

\begin{tabular}{l} 
Reverse \\
\hline 5'-TTGCCCTCCAATGGATCCT-3' \\
5'-TGCGCTGAGAATGTCCACTG-3' \\
5'-CCAGCCAGACCAATGAGATG-3' \\
5'-CACTGCCTTGCTTTTATTCTCACA-3' \\
5'-TACTCCATGAAAGTGGCAAAGC-3' \\
5'-TCATGCTGAAGATGGCTGAGA-3' \\
5'-GGTCGCTTAGTCCAACTTAATGAA-3' \\
5'-TGTTGGACTTAGCGGATCTTCTC-3' \\
5'-ACCACCAGTTGGTTGTCTTTG-3'
\end{tabular}

(adipose tissue, skeletal muscle, hypothalamus and liver) or 18s rRNA (Rn18s) (kidney), which were not altered by the obese $\mathrm{fa} / \mathrm{fa}$ genotype.

\section{Protein isolation for western blot and enzyme activity assay}

We chose epididymal adipose tissue as a typical representative of visceral fat. In comparison with other visceral fat depots, e.g. mesenteric and/or retroperitoneal, epididymal fat possesses the highest adipocyte cell size due to lower proliferative capacity. In addition, triglyceride turnover and oxidative stress predominate in epididymal fat tissue. Its enlargement in obesity contributes more significantly to overall metabolic disturbances (DiGirolamo et al. 1998, Sackmann-Sala et al. 2012).

Frozen adipose tissue and skeletal muscle samples were homogenised in ice-cold lysis buffer $(10 \mathrm{mM}$ Tris- $\mathrm{HCl}, \mathrm{pH}$ 8.0, $150 \mathrm{mM} \mathrm{NaCl}, 1 \%$ Nonidet P-40 (v/v), 0.5\% sodium deoxycholate (w/v), 0.1\% SDS (w/v), $0.5 \mathrm{mM}$ dithiothreitol (DTT), $1 \mathrm{mM}$ phenylmethylsulphonyl fluoride, $5 \mu \mathrm{g} / \mathrm{ml}$ leupeptin and $5 \mu \mathrm{g} / \mathrm{ml}$ aprotinin). Homogenates were placed on ice for $2 \mathrm{~h}$ with occasional mixing followed by centrifugation at $16000 \mathrm{~g} / 20 \mathrm{~min} / 4^{\circ} \mathrm{C}$. The supernatant was collected and used for western blot analysis. To evaluate the amount of phosphorylated eukaryotic elongation factor 2 (EEF2), adipose tissue samples were homogenised in $25 \mathrm{mM}$ HEPES buffer with a mixture of phosphatase inhibitors (10 mM sodium fluoride, $1 \mathrm{mM}$ sodium orthovanadate and $30 \mathrm{mM}$ sodium pyrophosphate) as described previously (Eckertova et al. 2011).

To determine enzymatic activity in the liver, kidney cortex, epididymal adipose tissue and musculus quadriceps membrane fraction, tissues were homogenised by a glass-Teflon homogeniser in a buffer containing $10 \mathrm{mM}$ Tris- $\mathrm{HCl}, \mathrm{pH} 7.4$, and $0.25 \mathrm{M}$ sucrose without protease inhibitors. Homogenates were then centrifuged at $1000 \mathrm{~g}$ for 10 min at $4{ }^{\circ} \mathrm{C}$ to remove the nuclear fraction and cell debris.
To obtain the membrane fraction, tissue supernatants underwent centrifugation at $16000 \mathrm{~g} / 15 \mathrm{~min} / 4^{\circ} \mathrm{C}$. Pellet was resuspended in $10 \mathrm{mM}$ Tris, $\mathrm{pH} 7.4$, and solubilised pellets containing the tissue membrane fraction were used for cystinyl aminopeptidase (oxytocinase) activity measurements. The protein concentration in all samples was determined by the BCA method (Sigma Aldrich).

\section{Western blot}

Samples were loaded and subjected to SDS-PAGE on $10 \%$ polyacrylamide gels. After electrophoretic separation, proteins were electro-transferred to a low-fluorescence PVDF membrane (Millipore). Equal loading was confirmed by Ponceau S staining of blotted membranes. Blots were blocked in 5\% non-fat milk $(\mathrm{w} / \mathrm{v})$ in Tris-buffered saline for $1 \mathrm{~h}$ at room temperature and then incubated overnight at $4{ }^{\circ} \mathrm{C}$ with primary antibody against oxytocin receptor (OXTR; H-60; sc-33209; Santa Cruz Biotechnology) diluted 1:400, phosphorylated EEF2 Thr56 (\#2331; Cell Signaling Technology, Danvers, MA, USA) diluted 1:1000 and/or total EEF2 (\#2332 Cell Signaling Technology) diluted $1: 1000$ in blocking buffer containing 0.1\% Igepal. $\beta$-actin (8H10D10; \#3700; Cell Signaling Technology) diluted 1:2000 or $\beta$-tubulin (926-42211; Li-Cor Biosciences, Lincoln, NE, USA) diluted 1:2000 were used as endogenous loading controls. After membrane washing, the signal of fluorescently labelled secondary anti-rabbit (\#5151) and/or anti-mouse (\#5257) antibodies (Cell Signaling Technology) diluted 1:15000 was detected using the Odyssey infrared imaging system (LI-COR Biosciences). Quantification of protein level was performed using Odyssey IR imaging system software version 2.0.

\section{Measurement of cystinyl aminopeptidase activity}

Cystinyl aminopeptidase activity was measured fluorometrically using an arylamide derivate as a substrate, as

Published by Bioscientifica Ltd 
Table 2 Selected metabolic parameters and adipose tissue phenotype of obese Zucker rats and their lean controls. Relative epididymal white adipose tissue (eWAT) weight was calculated as a ratio of absolute eWAT weight and the corresponding body weight of the animal. Expression of the gene of interest was normalised to that of the housekeeping gene encoding ribosomal protein S29 (Rps29). Data are presented as mean \pm s.E.M. Differences between obese $(n=7)$ and lean $(n=6)$ Zucker rats were analysed by Student's $t$-test

\begin{tabular}{|c|c|c|}
\hline & Lean $(+/ ?)$ & Obese (fa/fa) \\
\hline Body weight (g) & $457.3 \pm 8.7$ & $698.7 \pm 16.1^{\ddagger}$ \\
\hline Plasma leptin (ng/ml) & $6.3 \pm 0.7$ & $94.9 \pm 12.9^{\ddagger}$ \\
\hline Plasma insulin ( $\mathrm{ng} / \mathrm{ml})$ & $1.4 \pm 0.2$ & $14.1 \pm 2.0^{\ddagger}$ \\
\hline Fasting glycaemia $(\mathrm{mmol} / \mathrm{l})$ & $6.4 \pm 0.2$ & $6.9 \pm 0.2$ \\
\hline 2-h glycaemia $(\mathrm{mmol} / \mathrm{l})$ & $6.3 \pm 0.3$ & $9.5 \pm 1.02 *$ \\
\hline Triglycerides $(\mathrm{mmol} / \mathrm{l})$ & $0.78 \pm 0.04$ & $4.47 \pm 0.91^{\dagger}$ \\
\hline Cholesterol $(\mathrm{mmol} / \mathrm{l})$ & $2.53 \pm 0.06$ & $7.06 \pm 0.39^{\ddagger}$ \\
\hline LDL:HDL ratio & $0.29 \pm 0.01$ & $3.44 \pm 0.51^{\neq}$ \\
\hline Relative eWAT weight (\%) & $1.37 \pm 0.04$ & $2.84 \pm 0.15^{\ddagger}$ \\
\hline Cd68 mRNA (arbitrary units) & $0.10 \pm 0.03$ & $0.62 \pm 0.19 *$ \\
\hline Tnfa mRNA (arbitrary units) & $0.55 \pm 0.05$ & $0.98 \pm 0.10^{\dagger}$ \\
\hline I/10 mRNA (arbitrary units) & $0.41 \pm 0.09$ & $0.17 \pm 0.04^{*}$ \\
\hline Glut1 mRNA (arbitrary units) & $0.22 \pm 0.04$ & $0.53 \pm 0.07^{\dagger}$ \\
\hline
\end{tabular}

${ }^{*} P<0.05 ;{ }^{\dagger} P<0.01$ and ${ }^{\ddagger} P<0.001$. Glut1, glucose transporter $1 ; / / 10$, interleukin 10; Oxtr, oxytocin receptor; Syt4, synaptotagmin 4; Tnfa, tumour necrosis factor alpha.

described previously (Segarra et al. 2002). Briefly, plasma samples or the tissue membrane fraction were mixed with substrate solution containing $100 \mathrm{mM}$ arylamide derivate cystinyl- $\beta$-naphthylamide (Sigma Aldrich), $10 \mathrm{mg} / 100 \mathrm{ml}$ both BSA and DTT in $50 \mathrm{mM}$ Tris- $\mathrm{HCl}, \mathrm{pH}$ 6.0. The 96-well plate containing samples was placed in a fluorimeter (FLUOstar OPTIMA FL, BMG LabTech, Ortenberg, Germany) pre-heated to $37^{\circ} \mathrm{C}$ and enzyme kinetics were measured during $1 \mathrm{~h}$ as the amount of $\beta$-naphthylamine released as a result of enzymatic activity at wavelengths of $412 \mathrm{~nm}$ (emission) and $345 \mathrm{~nm}$ (excitation). Aminopeptidase activity is expressed as micromoles per liter of cys- $\beta$-naphthylamide hydrolysed per minute per milligram of protein.

\section{Statistical analysis}

Data are presented as mean \pm s.E.M. Data were tested for normality by the Kolmogorov-Smirnov test. Differences between lean and obese animals were analysed by Student's t-test. When data displayed a non-normal distribution, the Mann-Whitney $U$ test was used to analyse differences between experimental groups. The Pearson correlation test was used to analyse correlations between variables. The differences among groups were considered to be statistically significant when $P<0.05$.

\section{Results}

Obese Zucker rats displayed marked hyperleptinaemia, dyslipidaemia, hyperinsulinaemia and impaired glucose tolerance assessed by 2-h glycaemia during IPGTT but normal fasting glycaemia. In adipose tissue, upregulation of Cd68 mRNA, a marker of macrophages, elevated mRNA levels of pro-inflammatory cytokine tumour necrosis factor alpha (Tnfa) and at the same time decreased expression of anti-inflammatory cytokine interleukin 10 (Il10) were detected. Obesity in Zucker fatty rats was associated with increased mRNA expression of glucose transporter 1 (Slc2a1 (Glut1)) in adipose tissue. Baseline characteristics of experimental groups are shown in Table 2.

We observed a $40 \%$ reduction of plasma oxytocin levels (Fig. 1) in obese Zucker rats when compared with their lean controls. No correlation between plasma oxytocin and body weight within each group was found.

In order to evaluate oxytocin degradation and bioavailability, we measured the gene expression and activity of oxytocinase (cystinyl aminopeptidase) in plasma and peripheral tissues. Interestingly, the obese phenotype resulted in increased oxytocinase mRNA expression and activity in liver (Fig. 2A and B). In the kidney cortex, we observed increased oxytocinase expression at the mRNA level (Fig. 2A), but this change did not lead to elevated enzyme activity in the membrane fraction (Fig. 2B). Despite the unchanged oxytocinase mRNA expression in both adipose tissue and skeletal

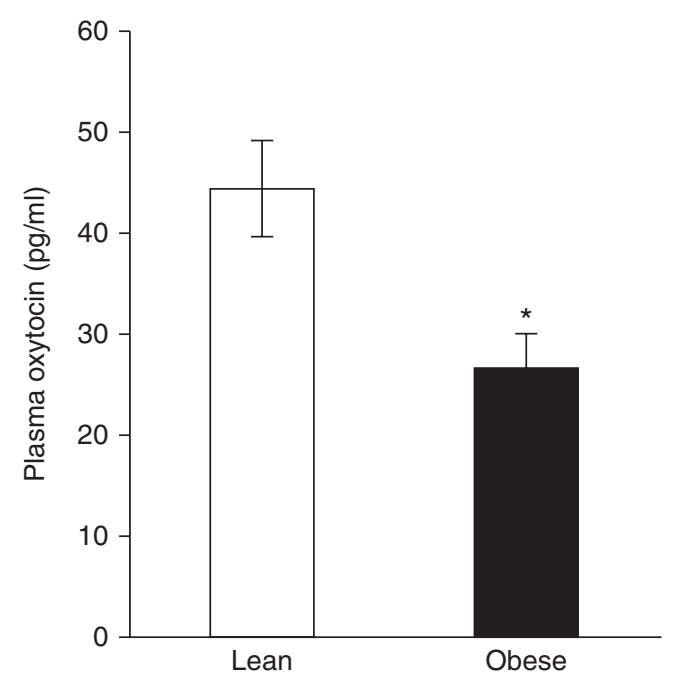

Figure 1

Plasma oxytocin levels. Oxytocin levels in plasma of lean and obese Zucker rats evaluated by EIA after peptide extraction. Data are expressed as mean \pm s.E.M. Differences between obese $(n=7)$ and lean $(n=6)$ Zucker rats were analysed by Student's $t$-test. ${ }^{*} P<0.05$.

Published by Bioscientifica Ltd. 

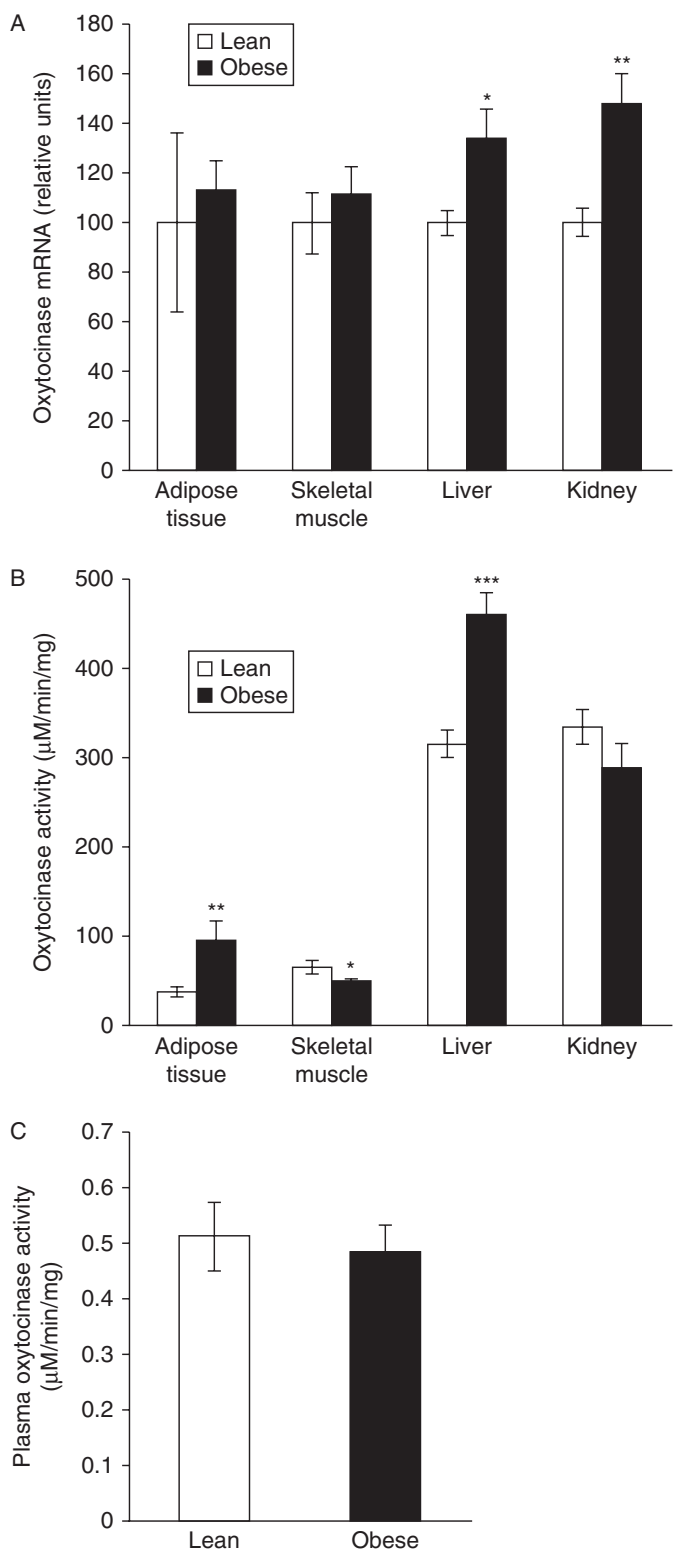

Figure 2

Oxytocinase expression and activity in peripheral tissues and plasma. (A) Oxytocinase mRNA expression levels in epididymal adipose tissue musculus quadriceps, liver and kidney cortex were determined by real-time PCR. Data were normalised to those for the housekeeping genes encoding ribosomal protein $\mathrm{S} 29$ (adipose tissue, skeletal muscle and liver) and 185 rRNA (Rn18s) (kidney cortex) whose expression was not significantly changed by the obese phenotype. Results are presented as a percentage change against control within the tissue and expressed as mean \pm s.E.M. Data were analysed by Student's $t$-test. ${ }^{*} P<0.05$ and $* * P<0.01$. (B) Oxytocinase activity in the plasma membrane fractions of adipose tissue, skeletal muscle, liver and kidney cortex. Data are expressed as mean \pm s.E.M. Differences between obese $(n=7)$ and lean $(n=6)$ Zucker rats were analysed by Student's $t$-test or Mann-Whitney $U$ test, when appropriate. ${ }^{*} P<0.05, * * P<0.01$ and $* * * P<0.001$. (C) Plasma oxytocinase activity in lean and obese Zucker rats determined by fluorometric assay using an arylamide derivate as a substrate. Data are expressed as mean \pm S.E.M. Differences between obese $(n=7)$ and lean $(n=6)$ Zucker rats were analysed by Student's $t$-test. Printed in Great Britain muscle (Fig. 2A), we observed a decline in skeletal muscle and an increase in adipose tissue oxytocinase activity in the plasma membrane fraction of obese Zucker rats (Fig. 2B) respectively. No difference in plasma oxytocinase activity between obese Zucker rats and lean controls was observed (Fig. 2C).

With the purpose of assessing oxytocin production, we measured hypothalamic oxytocin gene expression in lean and obese Zucker rats (Fig. 3). We observed more than twofold increase in oxytocin expression in the obese animals, although this difference did not reach significance due to high variability within the groups $(P=0.534)$. Gene expression of synaptotagmin 4 (Syt4), a negative regulator of oxytocin exocytosis, was not altered by the obese phenotype (Fig. 3). Hypothalamic expression of fat mass and obesity associated (Fto), a proposed transcription co-factor involved in regulation of oxytocin expression, displayed a tendency to increase $(P=0.064)$ in animals with the obese phenotype (Fig. 3).

We detected Oxtr mRNA as well as protein in epididymal adipose tissue and musculus quadriceps of rats (Fig. 4). In epididymal adipose tissue, both Oxtr mRNA (Fig. 4A) and protein level (Fig. 4B) were significantly upregulated in obese Zucker rats. However, despite the sevenfold increase in Oxtr mRNA level (Fig. 4A), we observed a more than $40 \%$ reduction in OXTR protein level (Fig. 4B) in the skeletal muscle of obese rats, although this change did not reach statistical significance $(P=0.066)$. In order to compare OXTR expression in adipose tissue and skeletal muscle, we loaded different

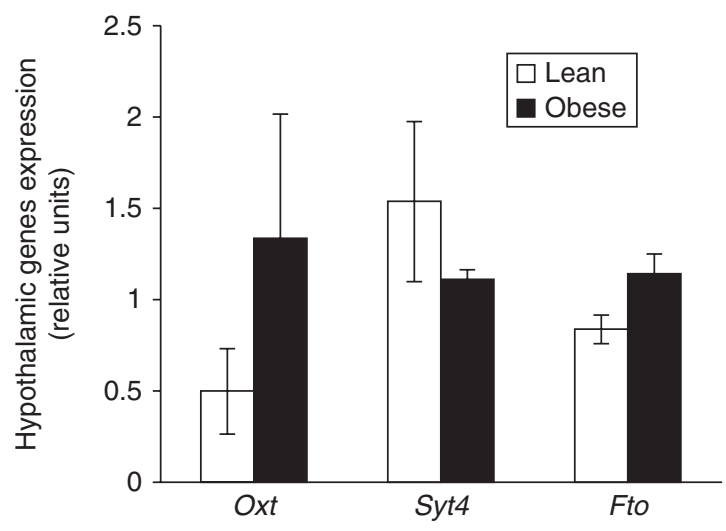

Figure 3

Expression of selected hypothalamic genes. Expression of genes of interest in the hypothalamus of lean and obese Zucker rats measured by real-time PCR. Data were normalised to that for the housekeeping gene encoding ribosomal protein $\$ 29$ whose expression was not significantly changed by the obese phenotype. Data are expressed as mean \pm s.E.M. Differences between obese $(n=7)$ and lean $(n=6)$ Zucker rats were analysed by Student's $t$-test.

Published by Bioscientifica Ltd 
quantities of adipose tissue and skeletal muscle homogenates from the same lean individual for western blot analysis. We found that OXTR protein expression was approximately ninefold higher $(9.21 \pm 0.91)$ in adipose tissue than in skeletal muscle (Fig. 4C). When correlating OXTR protein with oxytocin plasma levels, a highly significant negative relation was found in epididymal adipose tissue (Fig. 4D) in contrast to no correlation in quadriceps muscle (data not shown). Moreover, a strong positive correlation $(r=0.83 ; n=13 ; P<0.001)$ was found between Oxtr and Cd68 mRNA expression in adipose tissue. This correlation disappeared when the lean group
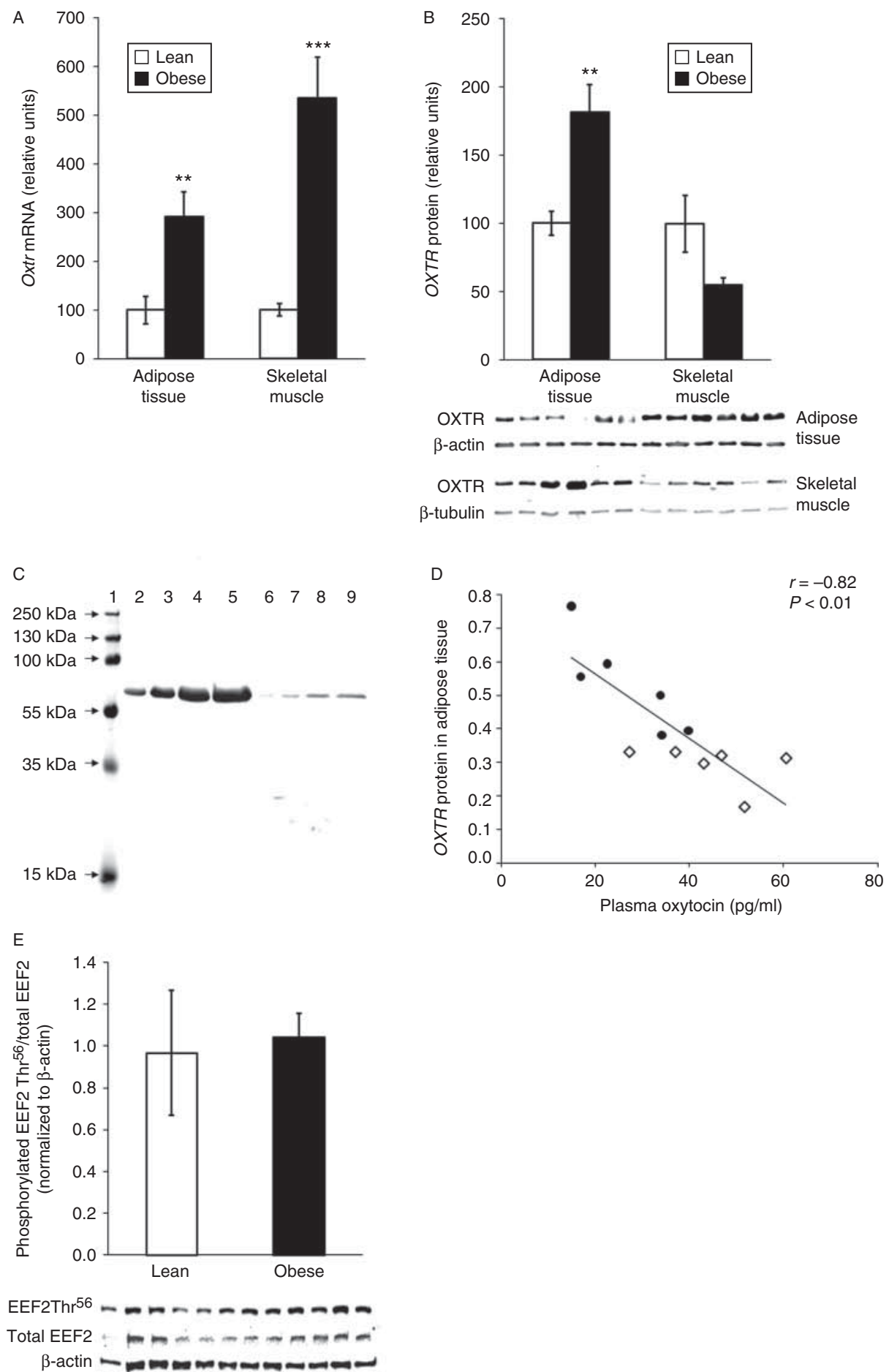
alone was analysed $(r=-0.30 ; n=6 ; P=0.56)$ but persisted within the obese group $(r=0.82 ; n=7 ; P<0.05)$. To consider entire epididymal adipose tissue sensitivity to plasma oxytocin, we determined phosphorylation of the oxytocin downstream signalling molecule, EEF2. Western blot analysis revealed no changes in phosphorylation of EEF2 in the obese phenotype animals (Fig. 4E).

\section{Discussion}

This study reveals a modification of the oxytocin system without clear implications in the oxytocin signalling in 33-week-old obese insulin-resistant Zucker rats. In spite of being a genetic model of obesity (Phillips et al. 1996), Zucker fatty rats represent an appropriate model for studying human obesity, as related metabolic comorbidities associated with obesity also develop. In addition, the adipose tissue of obese Zucker rats displays characteristics typical of human obesity such as tissue inflammation and hypoxia.

The obesity-associated hypooxytocinaemia observed in our study is consistent with the previously observed tendency towards a reduction of plasma oxytocin levels in high-fat-diet-induced obesity (Morton et al. 2012).

Recent research has linked circadian arrhythmicity to obesity and related diseases (Bray \& Young 2007, Froy 2010). In rodents, a high-fat diet promotes daytime rather than night-time caloric intake leading to feeding circadian arrhythmicity. It has been well documented that hyperphagy in obese Zucker rats is manifested by increasing meal size during the light phase (Becker \& Grinker 1977, Fukagawa et al. 1992, Mistlberger et al. 1998). Hypothalamic release of anorexigenic oxytocin displays a diurnal rhythm of daytime rise and night-time decline, which is abrogated in high-fat-diet-induced obesity (Zhang \& Cai 2011). As we measured oxytocin in blood obtained from decapitation at daytime, the reduced oxytocinaemia corresponds to the observed daytime decline in obese animals and supports that attenuated oxytocin manifestation contributes to energy imbalance.

Obese and normal-weight men display similar basal oxytocin levels and weight reduction is not accompanied by a change in plasma oxytocin (Coiro et al. 1988). On the other hand, Stock et al. (1989) showed that the plasma oxytocin levels were fourfold higher in obese subjects compared with controls regardless of sex. Following gastric banding and substantial weight loss of the obese individuals, the oxytocin levels in plasma were reduced.

The absence of a correlation between plasma oxytocin and body weight within a single group observed in this study is in line with a previous result showing no relation between oxytocinaemia and BMI or body fat (Hoybye et al. 2003). This observation implies that obesity affects plasma oxytocin secondarily rather than changes in oxytocin levels affecting body weight. On the other hand, studies using oxytocin and/or OXTR-deficient mice have shown that a lack of oxytocin action is accompanied by the development of obesity and impaired glucose tolerance (Takayanagi et al. 2008, Camerino 2009). In addition, the beneficial effects of oxytocin treatment, such as weight loss, have been well documented recently (Deblon et al. 2011, Maejima et al. 2011). These facts imply at least a partial role of oxytocin in the development of obesity.

Recently, Szeto et al. (2011) emphasised a critical need to establish valid and reliable methods to measure plasma oxytocin. In this regard, plasma extraction is the basic

\section{Figure 4}

Expression of oxytocin receptor (OXTR) in adipose tissue and skeletal muscle. (A) Oxtr mRNA expression in epididymal adipose tissue and musculus quadriceps of lean and obese Zucker rats determined by real-time PCR. Data were normalised to those for the housekeeping gene encoding ribosomal protein S29 whose expression was not significantly changed by the obese phenotype neither in adipose tissue nor in skeletal muscle. Results are presented as a percentage change against control levels within the tissue and expressed as mean \pm s.E.M. Differences between obese $(n=7)$ and lean $(n=6)$ Zucker rats were analysed by Student's $t$-test or Mann-Whitney $U$ test, when appropriate. ${ }^{*} P<0.01$ and $* * * P<0.001$. (B) Protein level of OXTR in total homogenates of epididymal adipose tissue and musculus quadriceps evaluated by western blot. Densitometric quantification of results for signals corresponding to OXTR were normalised to those for the endogenous loading controls $\beta$-actin (adipose tissue) or $\beta$-tubulin (skeletal muscle). Representative blots are shown at the bottom of the figure. From the left, the first six bands represent lean and the next six ones obese animals. Results are presented as a percentage change against control levels within the tissue and expressed as mean \pm s.E.M. Differences between obese $(n=6)$ and lean
( $n=6)$ Zucker rats were analysed by Student's $t$-test. $* * P<0.01$.

(C) A comparison of OXTR protein expression in adipose tissue and skeletal muscle of the same lean individual evaluated by western blot. Lane 1: protein ladder; lanes 2-5: epididymal adipose tissue total homogenate (5, 10, 20 and $30 \mu \mathrm{g})$; lanes 6-9: quadriceps muscle total homogenate $(5,10,20$ and $30 \mu \mathrm{g})$. The expected molecular weight of OXTR protein was $66 \mathrm{kDa}$ (antibody datasheet sc-33209). (D) Correlation between plasma oxytocin levels and OXTR protein in epididymal adipose tissue of lean (open squares) and obese rats (filled circles). Data were statistically analysed using the Pearson correlation test $(n=12)$. (E) Protein level of eukaryotic elongation factor 2 (EEF2) in epididymal adipose tissue of lean and obese Zucker rats evaluated by western blot. The phosphorylated to total EEF2 ratio was normalised to the endogenous loading control $\beta$-actin. Representative blots are shown at the bottom of the figure. From the left, the first six bands represent lean and the next six ones obese animals. Results are expressed as mean \pm s.E.M. Differences between obese $(n=6)$ and lean $(n=6)$ Zucker rats were analysed by Student's $t$-test. http://joe.endocrinology-journals.org DOI: 10.1530/JOE-13-0417
() 2014 Society for Endocrinology Printed in Great Britain
Published by Bioscientifica Ltd 
condition in order to remove higher molecular weight immunoreactive contaminants from the sample before an antibody-based oxytocin assay is employed (Szeto et al. 2011). However, even extracted plasma samples might contain low-molecular-mass immunoreactive contaminants, most probably the degradation products of oxytocin. Mass-spectrometry-based methods seem to be a good, yet expensive and not always accessible, solution for reliable oxytocin quantification. In summary, methodological differences in oxytocin determination might be responsible for the variability in oxytocin response to obesity described in different studies. Interpretation of oxytocin data must therefore take into account the limitations of the quantification methods employed. In this study, plasma samples pre-purified on a C-18 column were used for EIA evaluation.

Oxytocinase regulates circulating oxytocin levels and its biological activity in tissues via inactivation of the peptide by hydrolysis of cysteine-tyrosine bonds (Rogi et al. 1996, Keller 2003). Importantly, increased oxytocinase expression and activity in the liver of obese Zucker rats implies a higher rate of oxytocin cleavage, indicating limited bioavailability of the peptide due to its degradation. In contrast, in the kidney, despite the elevated levels of oxytocinase mRNA, no changes in the enzyme activity were observed. It seems that the kidney is not involved in the elevated oxytocin degradation in obesity. Similarly, plasma oxytocinase activity did not participate in increased oxytocin degradation in our model of obesity. The same results were found by Ramirez et al. (1998) in olive-oil-fed mice.

Oxytocinase has been shown to be identical to insulin-regulated aminopeptidase (IRAP). In insulinresponsive tissues, IRAP is almost exclusively co-localised with the insulin-regulated glucose transporter GLUT4, which is retained in intracellular compartments in the basal state or translocates with GLUT4 to the plasma membrane upon insulin stimulation (Keller et al. 1995, Rogi et al. 1996). The decline in IRAP/oxytocinase activity in the skeletal muscle membrane fraction of obese rats confirms impaired muscle insulin sensitivity in these rats. The increased IRAP/oxytocinase activity in the epididymal adipose tissue membrane fraction of obese rats is consistent with previously described abnormal subcellular adipocyte IRAP/oxytocinase distribution and accumulation in the plasma membrane fraction under basal conditions when glucose homeostasis is disrupted in humans (Maianu et al. 2001). Concomitantly with the appearance of IRAP/oxytocinase at the cell surface, aminopeptidase activity toward extracellular substrates increases (Keller 2003). Thus, the increased oxytocinase activity in the plasma membrane fraction implies higher oxytocin processing in the epididymal adipose tissue of obese rats. Considering the multiple fat mass expansions in obesity, increased oxytocinase activity in the adipose tissue of obese Zucker rats may significantly contribute to the low plasma levels of oxytocin.

Our hypothesis that oxytocin degradation rather than lowered oxytocin production and/or secretion accounts for decreased plasma oxytocin levels in obesity is supported by the unchanged expression of the oxytocin gene as well as Syt4 in the hypothalamus of obese Zucker rats compared with lean ones. Recently, it has been clearly demonstrated that Syt4 is predominantly expressed in oxytocin neurons and serves as a negative regulator of oxytocin release (Zhang et al. 2011). In contrast, Zhang et al. (2011) observed upregulation of both Syt4 and the oxytocin gene together with decreased oxytocin release in hypothalami of obese mice fed with a high-fat diet. However, oxytocin degradation was not studied in the above-mentioned paper. Thus, one apparently cannot exclude the contribution of peripheral oxytocin degradation to the decline in plasma oxytocin in the mouse model of obesity induced by a high-fat diet. The product of the fat mass and obesity associated gene has been shown to colocalise with oxytocin neurons. Moreover, FTO positively regulates expression of the gene encoding oxytocin (Olszewski et al. 2011). Thus, the hypothalamic Fto mRNA level is consistent with observed the unchanged oxytocin expression. We might conclude that hypothalamic oxytocin production and release is not affected in obese Zucker rats.

The physiological effects of oxytocin are mediated via interaction with its $G_{q}$ protein-coupled receptor. Only one isoform of the OXTR, widely expressed throughout the whole body, has been identified (Devost et al. 2008). The OXTR was also detected in 3T3-L1 pre-adipocytes/ adipocytes and isolated rat fat cells (Bonne \& Cohen 1975, Boland \& Goren 1987, Schaffler et al. 2005), as well as in the $\mathrm{C} 2 \mathrm{C} 12$ mouse myoblast cell line and human myoblasts (Breton et al. 2002, Lee et al. 2008); however, OXTR was not identified in the skeletal muscle of rams (Whittington et al. 2001). We confirmed the presence of OXTR in vivo in insulin-sensitive tissues at both the mRNA and protein level and found that the receptor expression in these tissues was differentially regulated by obesity. To our knowledge, there are no other studies on the regulation of OXTR expression in adipose tissue and/or skeletal muscle in obesity and insulin resistance. Moreover, this is the first evidence, to our knowledge, that OXTR is much more expressed in adipose tissue than in skeletal muscle. Low expression of OXTR in skeletal muscle could be an

Published by Bioscientifica Ltd. 
explanation for OXTR not being detected in skeletal muscle of other species (Whittington et al. 2001). Based on the marked difference in tissue OXTR expression, we suggest that there is a more pronounced oxytocin effect on adipose tissue than that on skeletal muscle.

Oxytocin stimulates glucose uptake in skeletal muscle cells (Lee et al. 2008) and stimulates myoblast fusion and myotube formation (Breton et al. 2002). Thus, the decreased plasma oxytocin together with reduced OXTR in the skeletal muscle of Zucker fatty rats may contribute to reduced muscle mass (Kemp et al. 2009) and the reduced muscle glucose disposal observed in obesity and insulin resistance (King et al. 1992). Based on muscle OXTR protein data and muscle membrane oxytocinase activity, we conclude that there is reduced oxytocin processing in the tissue under the conditions of obesity.

Oxtr mRNA is upregulated during differentiation of 3T3-L1 pre-adipocyte into mature adipocytes (Schaffler et al. 2005). Adipose tissue of obese Zucker rats expands both by hypertrophy and by hyperplasia (Johnson et al. 1978, Kaplan et al. 1980). Therefore, the rise in OXTR levels could be linked to increased adipocyte cell numbers. However, upregulation of the OXTR may simply be an adaptation of adipose tissue to decreased hormone levels in the circulation. This is in accordance with the observed strong negative correlation between plasma oxytocin levels and OXTR protein in epididymal adipose tissue. To assess the sensitivity of adipose tissue to plasma oxytocin, we checked possible oxytocin downstream signalling. Recently, we have clearly demonstrated EEF2 dephosphorylation in rat epididymal adipose tissue upon oxytocin treatment (Eckertova et al. 2011). The absence of a change in EEF2 phosphorylation in adipose tissue homogenate of obese Zucker rats indicates similar activation of the oxytocin signalling pathway. We may suppose that decreased plasma oxytocin levels in Zucker fatty rats are compensated for by higher OXTR expression in adipose tissue. However, we cannot exclude the possibility of macrophage infiltration as revealed by upregulated transcription of $C d 68$ in adipose tissue of obese rats, which may account for increased OXTR expression. This is supported by the presence of OXTR in macrophages (Szeto et al. 2008) and by the observed strong positive correlation between Cd68 and Oxtr in adipose tissue in our study.

In conclusion, our study provides clear evidence that the oxytocin system is significantly altered in 33-week-old Zucker fatty rats, an animal model of obesity and insulin resistance. Reduced plasma oxytocin levels are most probably a result of higher oxytocin degradation by the liver and expanded adipose tissue in obese animals.
In addition, these changes are accompanied by altered expression of the OXTR in adipose tissue and skeletal muscle. Thus, our understanding of the physiological effects of oxytocin is changing as the biological significance of the oxytocin system extends far beyond the reproductive system. The results presented are likely to motivate further research into human obesity as there is a gap in the knowledge regarding the regulation of oxytocinase and OXTR.

\section{Declaration of interest}

The authors declare that there is no conflict of interest that could be perceived as prejudicing the impartiality of the research reported.

\section{Funding}

This work was supported by the grants APVV 0028-10 and CE NOREG (Slovakia) and the National Science Centre 2011/01M/NZ04/03752 (Poland).

\section{Author contribution statement}

$L G$ prepared major parts of the manuscript and carried out analyses of western blots. $\mathrm{L} G$ and $\mathrm{K} \mathrm{K}$ conducted real-time PCR analyses and data interpretation. A B S and L G carried out measurements of enzyme activity and the literature search. A S carried out analyses of the hypothalamus. $\mathrm{M} \mathrm{S}$ and $\mathrm{L} \mathrm{G}$ conducted glucose tolerance tests and biochemical analyses. $\mathrm{R} O$ and $\mathrm{S} Z \mathrm{Z}$ planned and organised the study and contributed to the revisions and the final drafts of the manuscript. All authors have read and approved the final manuscript.

\section{Acknowledgements}

The authors acknowledge Mrs Katarina Vrzalova's technical assistance.

\section{References}

Becker EE \& Grinker JA 1977 Meal patterns in the genetically obese Zucker rat. Physiology \& Behavior 18 685-692. (doi:10.1016/00319384(77)90067-1)

Boland D \& Goren HJ 1987 Binding and structural properties of oxytocin receptors in isolated rat epididymal adipocytes. Regulatory Peptides 18 7-18. (doi:10.1016/0167-0115(87)90045-0)

Bonne D \& Cohen P 1975 Characterization of oxytocin receptors on isolated rat fat cells. European Journal of Biochemistry 56 295-303. (doi:10.1111/j.1432-1033.1975.tb02233.x)

Bray MS \& Young ME 2007 Circadian rhythms in the development of obesity: potential role for the circadian clock within the adipocyte. Obesity Reviews 8 169-181. (doi:10.1111/j.1467-789X.2006.00277.x)

Breton C, Haenggeli C, Barberis C, Heitz F, Bader CR, Bernheim L \& Tribollet E 2002 Presence of functional oxytocin receptors in cultured human myoblasts. Journal of Clinical Endocrinology and Metabolism $\mathbf{8 7}$ 1415-1418. (doi:10.1210/jc.87.3.1415)

Camerino C 2009 Low sympathetic tone and obese phenotype in oxytocindeficient mice. Obesity 17 980-984. (doi:10.1038/oby.2009.12)

Coiro V, Passeri M, Davoli C, d'Amato L, Gelmini G, Fagnoni F, Schianchi L, Bentivoglio M, Volpi R \& Chiodera P 1988 Oxytocin response to insulin-induced hypoglycemia in obese subjects before and after weight loss. Journal of Endocrinological Investigation 11 125-128. http://joe.endocrinology-journals.org DOI: $10.1530 / J O E-13-0417$ (c) 2014 Society for Endocrinology Printed in Great Britain
Published by Bioscientifica Ltd. 
Deblon N, Veyrat-Durebex C, Bourgoin L, Caillon A, Bussier AL, Petrosino S, Piscitelli F, Legros JJ, Geenen V, Foti M et al. 2011 Mechanisms of the anti-obesity effects of oxytocin in diet-induced obese rats. PLOS ONE 6 e25565. (doi:10.1371/journal.pone.0025565)

Devost D, Wrzal P \& Zingg HH 2008 Oxytocin receptor signalling. Progress in Brain Research 170 167-176. (doi:10.1016/S0079-6123(08)00415-9)

DiGirolamo M, Fine JB, Tagra K \& Rossmanith R 1998 Qualitative regional differences in adipose tissue growth and cellularity in male Wistar rats fed ad libitum. American Journal of Physiology 274 R1460-R1467.

Eckertova M, Ondrejcakova M, Krskova K, Zorad S \& Jezova D 2011 Subchronic treatment of rats with oxytocin results in improved adipocyte differentiation and increased gene expression of factors involved in adipogenesis. British Journal of Pharmacology 162 452-463. (doi:10.1111/j.1476-5381.2010.01037.x)

Fjellestad-Paulsen A \& Lundin S 1996 Metabolism of vasopressin, oxytocin and their analogues $\left[\mathrm{Mpa}^{1}, \mathrm{D}^{-} \mathrm{Arg}^{8}\right]$-vasopressin (dDAVP) and $\left[\mathrm{Mpa}^{1}\right.$, D-Tyr(Et) $\left.{ }^{2}, \mathrm{Thr}^{4}, \mathrm{Orn}^{8}\right]$-oxytocin (antocin) in human kidney and liver homogenates. Regulatory Peptides 67 27-32. (doi:S0167-0115(96)00103-6)

Froy O 2010 Metabolism and circadian rhythms - implications for obesity. Endocrine Reviews 31 1-24. (doi:10.1210/er.2009-0014)

Fukagawa K, Sakata T, Yoshimatsu H, Fujimoto K, Uchimura K \& Asano C 1992 Advance shift of feeding circadian rhythm induced by obesity progression in Zucker rats. American Journal of Physiology 263 R1169-R1175.

Gimpl G \& Fahrenholz F 2001 The oxytocin receptor system: structure, function, and regulation. Physiological Reviews 81 629-683.

Gutkowska J, Jankowski M, Mukaddam-Daher S \& McCann SM 2000 Oxytocin is a cardiovascular hormone. Brazilian Journal of Medical and Biological Research 33 625-633. (doi:10.1590/S0100-879X2000000 600003)

Hoybye C, Barkeling B, Espelund U, Petersson M \& Thoren M 2003 Peptides associated with hyperphagia in adults with Prader-Willi syndrome before and during GH treatment. Growth Hormone \& IGF Research 13 322-327. (doi:10.1016/S1096-6374(03)00077-7)

Jezova D, Skultetyova I, Tokarev DI, Bakos P \& Vigas M 1995 Vasopressin and oxytocin in stress. Annals of the New York Academy of Sciences 771 192-203. (doi:10.1111/j.1749-6632.1995.tb44681.x)

Johnson PR, Stern JS, Greenwood MR \& Hirsch J 1978 Adipose tissue hyperplasia and hyperinsulinemia on Zucker obese female rats: a developmental study. Metabolism 27 1941-1954. (doi:10.1016/S00260495(78)80011-0)

Kaplan ML, Trout JR \& Smith P 1980 Adipocyte size distribution in fa/fa rats during development. Metabolism 29 333-339. (doi:10.1016/00260495(80)90006-2)

Keller SR 2003 The insulin-regulated aminopeptidase: a companion and regulator of GLUT4. Frontiers in Bioscience 8 s410-s420. (doi:10.2741/1078)

Keller SR, Scott HM, Mastick CC, Aebersold R \& Lienhard GE 1995 Cloning and characterization of a novel insulin-regulated membrane aminopeptidase from Glut4 vesicles. Journal of Biological Chemistry $\mathbf{2 7 0}$ 23612-23618. (doi:10.1074/jbc.270.35.20497)

Kemp JG, Blazev R, Stephenson DG \& Stephenson GM 2009 Morphological and biochemical alterations of skeletal muscles from the genetically obese $(o b / o b)$ mouse. International Journal of Obesity 33 831-841. (doi:10.1038/ijo.2009.100)

King PA, Horton ED, Hirshman MF \& Horton ES 1992 Insulin resistance in obese Zucker rat (fa/fa) skeletal muscle is associated with a failure of glucose transporter translocation. Journal Clinical Investigation 90 1568-1575. (doi:10.1172/JCI116025)

Lee ES, Uhm KO, Lee YM, Kwon J, Park SH \& Soo KH 2008 Oxytocin stimulates glucose uptake in skeletal muscle cells through the calciumCaMKK-AMPK pathway. Regulatory Peptides 151 71-74. (doi:10.1016/ j.regpep.2008.05.001)

Leng G, Onaka T, Caquineau C, Sabatier N, Tobin VA \& Takayanagi Y 2008 Oxytocin and appetite. Progress in Brain Research 170 137-151. (doi:10.1016/S0079-6123(08)00413-5)
Maejima Y, Iwasaki Y, Yamahara Y, Kodaira M, Sedbazar U \& Yada T 2011 Peripheral oxytocin treatment ameliorates obesity by reducing food intake and visceral fat mass. Aging 3 1169-1177.

Maianu L, Keller SR \& Garvey WT 2001 Adipocytes exhibit abnormal subcellular distribution and translocation of vesicles containing glucose transporter 4 and insulin-regulated aminopeptidase in type 2 diabetes mellitus: implications regarding defects in vesicle trafficking. Journal of Clinical Endocrinology and Metabolism 86 5450-5456.

Mistlberger RE, Lukman H \& Nadeau BG 1998 Circadian rhythms in the Zucker obese rat: assessment and intervention. Appetite 30 255-267. (doi:10.1006/appe.1997.0134)

Morton GJ, Thatcher BS, Reidelberger RD, Ogimoto K, Wolden-Hanson T, Baskin DG, Schwartz MW \& Blevins JE 2012 Peripheral oxytocin suppresses food intake and causes weight loss in diet-induced obese rats. American Journal of Physiology. Endocrinology and Metabolism 302 E134-E144. (doi:10.1152/ajpendo.00296.2011)

Olszewski PK, Fredriksson R, Eriksson JD, Mitra A, Radomska KJ, Gosnell BA, Solvang MN, Levine AS \& Schioth HB 2011 Fto colocalizes with a satiety mediator oxytocin in the brain and upregulates oxytocin gene expression. Biochemical and Biophysical Research Communications 408 422-426. (doi:10.1016/j.bbrc.2011.04.037)

Ondrejcakova M, Ravingerova T, Bakos J, Pancza D \& Jezova D 2009 Oxytocin exerts protective effects on in vitro myocardial injury induced by ischemia and reperfusion. Canadian Journal of Physiology and Pharmacology 87 137-142. (doi:10.1139/Y08-108)

Phillips MS, Liu Q, Hammond HA, Dugan V, Hey PJ, Caskey CJ \& Hess JF 1996 Leptin receptor missense mutation in the fatty Zucker rat. Nature Genetics 13 18-19. (doi:10.1038/ng0596-18)

Ramirez MJ, Martinez JM, Prieto I, Alba F \& Ramirez M 1998 Dietary supplementation with olive oil influences aminopeptidase activities in mice. Nutrition Research 18 99-107. (doi:10.1016/S0271-5317 (97)00204-2)

Rogi T, Tsujimoto M, Nakazato H, Mizutani S \& Tomoda Y 1996 Human placental leucine aminopeptidase/oxytocinase. A new member of type II membrane-spanning zinc metallopeptidase family. Journal of Biological Chemistry 271 56-61. (doi:10.1074/jbc.271.1.56)

Sackmann-Sala L, Berryman DE, Munn RD, Lubbers ER \& Kopchick JJ 2012 Heterogeneity among white adipose tissue depots in male C57BL/6J mice. Obesity 20 101-111. (doi:10.1038/oby.2011.235)

Schaffler A, Binart N, Scholmerich J \& Buchler C 2005 Hypothesis paper brain talks with fat-evidence for a hypothalamic-pituitary-adipose axis? Neuropeptides 39 363-367. (doi:10.1016/j.npep.2005.06.003)

Schroeder M, Zagoory-Sharon O, Shbiro L, Marco A, Hyun J, Moran TH, Bi S \& Weller A 2009 Development of obesity in the Otsuka Long-Evans Tokushima Fatty rat. American Journal of Physiology. Regulatory, Integrative and Comparative Physiology 297 R1749-R1760. (doi:10.1152/ ajpregu.00461.2009)

Segarra AB, Arechaga G, Prieto I, Ramirez-Exposito MJ, Martinez-Martos JM, Ramirez M, Alba F, Ruiz-Larrea MB \& Ruiz-Sanz JI 2002 Effects of dietary supplementation with fish oil, lard, or coconut oil on oxytocinase activity in the testis of mice. Archives of Andrology 48 233-236. (doi:10.1080/01485010252869333)

Sjoholm I \& Ryden G 1996 Uptake of oxytocin in tissues after intravenous administration of tritiated oxytocin in rats. Acta Endocrinologica (Copenhagen) 61 432-440. (doi:10.1530/acta.0.0610432)

Stock S, Granstrom L, Backman L, Matthiesen AS \& Uvnas-Moberg K 1989 Elevated plasma levels of oxytocin in obese subjects before and after gastric banding. International Journal of Obesity 13 213-222.

Szeto A, Nation DA, Mendez AJ, Dominguez-Bendala J, Brooks LG, Schneiderman N \& McCabe PM 2008 Oxytocin attenuates NADPHdependent superoxide activity and IL- 6 secretion in macrophages and vascular cells. American Journal of Physiology. Endocrinology and Metabolism 295 E1495-E1501. (doi:10.1152/ajpendo.90718.2008)

Szeto A, McCabe PM, Nation DA, Tabak BA, Rossetti MA, McCullough ME, Schneiderman N \& Mendez AJ 2011 Evaluation of enzyme immunoassay and radioimmunoassay methods for the measurement of plasma 
oxytocin. Psychosomatic Medicine 73 393-400. (doi:10.1097/PSY 0b013e31821df0c2)

Takayanagi Y, Kasahara Y, Onaka T, Takahashi N, Kawada T \& Nishimori K 2008 Oxytocin receptor-deficient mice developed late-onset obesity. Neuroreport 19 951-955. (doi:10.1097/WNR.0b013e3283021ca9)

Wallis MG, Lankford MF \& Keller SR 2007 Vasopressin is a physiological substrate for the insulin-regulated aminopeptidase IRAP. American Journal of Physiology. Endocrinology and Metabolism 293 E1092-E1102. (doi:10.1152/ajpendo.00440.2007)

Whittington K, Assinder SJ, Parkinson T, Lapwood KR \& Nicholson HD 2001 Function and localization of oxytocin receptors in the reproductive tissue of rams. Reproduction 122 317-325. (doi:10.1530/rep.0. 1220317)
Zhang G \& Cai D 2011 Circadian intervention of obesity development via resting-stage feeding manipulation or oxytocin treatment. American Journal of Physiology. Endocrinology and Metabolism 301 E1004-E1012. (doi:10.1152/ajpendo.00196.2011)

Zhang G, Bai H, Zhang H, Dean C, Wu Q, Li J, Guariglia S, Meng Q \& Cai D 2011 Neuropeptide exocytosis involving synaptotagmin-4 and oxytocin in hypothalamic programming of body weight and energy balance. Neuron 69 523-535. (doi:10.1016/j.neuron.2010. 12.036)

Zhang H, Wu C, Chen Q, Chen X, Xu Z, Wu J \& Cai D 2013 Treatment of obesity and diabetes using oxytocin or analogs in patients and mouse models. PLOS ONE 8 e61477. (doi:10.1371/journal.pone. 0061477)

Received in final form 20 December 2013

Accepted 2 January 2014

Accepted Preprint published online 3 January 2014
Published by Bioscientifica Ltd. 